\title{
Valid and reliable instruments for arm-hand assessment at ICF activity level in persons with hemiplegia: a systematic review
}

Ryanne JM Lemmens ${ }^{1,2^{*}}$, Annick AA Timmermans ${ }^{1,2}$, Yvonne JM Janssen-Potten ${ }^{1,2}$, Rob JEM Smeets ${ }^{1,2,3}$ and Henk AM Seelen ${ }^{1,2}$

\begin{abstract}
Background: Loss of arm-hand performance due to a hemiparesis as a result of stroke or cerebral palsy (CP), leads to large problems in daily life of these patients. Assessment of arm-hand performance is important in both clinical practice and research. To gain more insight in e.g. effectiveness of common therapies for different patient populations with similar clinical characteristics, consensus regarding the choice and use of outcome measures is paramount. To guide this choice, an overview of available instruments is necessary. The aim of this systematic review is to identify, evaluate and categorize instruments, reported to be valid and reliable, assessing arm-hand performance at the ICF activity level in patients with stroke or cerebral palsy.
\end{abstract}

Methods: A systematic literature search was performed to identify articles containing instruments assessing armhand skilled performance in patients with stroke or cerebral palsy. Instruments were identified and divided into the categories capacity, perceived performance and actual performance. A second search was performed to obtain information on their content and psychometrics.

Results: Regarding capacity, perceived performance and actual performance, 18, 9 and 3 instruments were included respectively. Only 3 of all included instruments were used and tested in both patient populations. The content of the instruments differed widely regarding the ICF levels measured, assessment of the amount of use versus the quality of use, the inclusion of unimanual and/or bimanual tasks and the inclusion of basic and/or extended tasks.

Conclusions: Although many instruments assess capacity and perceived performance, a dearth exists of instruments assessing actual performance. In addition, instruments appropriate for more than one patient population are sparse. For actual performance, new instruments have to be developed, with specific focus on the usability in different patient populations and the assessment of quality of use as well as amount of use. Also, consensus about the choice and use of instruments within and across populations is needed.

Keywords: Rehabilitation, Stroke, Cerebral Palsy, Arm, Hand, Outcome assessment, Activities of daily living, Activity, Capacity, Performance

\section{Background}

Regarding arm-hand training, most treatment approaches target a specific patient population, and almost all armhand assessment instruments are currently applied in only one particular pathology. This leads to a myriad of patient-specific assessment tools. However, patients with

\footnotetext{
* Correspondence: ryanne.lemmens@maastrichtuniversity.nl

'Research School CAPHRI, Department of Rehabilitation Medicine, Maastricht University, Maastricht, the Netherlands

Full list of author information is available at the end of the article
}

different disorders with similar clinical characteristics might benefit from similar treatments, and assessment instruments might be suitable for more than one patient population. Dobkin [1] stated that the mechanisms of motor control, cognitive control and neural adaptation that accompany training and learning are not as much dependent on the underlying disease as on the spared nodes within neural networks. To enable a comparison of treatments within one patient population, and to gain more insight in the possibilities of common therapies for

\section{() Biomed Central}


different patient populations with similar clinical characteristics, consensus should be reached regarding the choice and use of outcome measures that can be used across pathologies. Two disorders with similar clinical characteristics are stroke and cerebral palsy (CP). Whereas stroke is most prevalent in adults, CP is a neurologic disorder arising early in the development of children, i.e. during pregnancy, childbirth or early infancy [2]. Hemiparesis, spasticity and coordination disorders occur in both patients with stroke and patients with CP.

In stroke and CP, loss of arm-hand function and, consequently, loss of arm-hand performance leads to large problems in the everyday life of these patients. It limits the execution of activities of daily living, which results in greater dependency, restricted social participation [3], and a decreased quality of life [4]. After discharge from the hospital or rehabilitation centre, arm-hand function is often not fully recovered in patients with stroke [5] or CP [6]. Four years after stroke, $67 \%$ of the patients experience the non-use or disuse of the affected arm as a major problem, whereas only $6 \%$ of the patients is satisfied with their arm-hand function [7]. For CP, about $60 \%$ of the children between 4 and 16 years old have problems with their arm-hand function during daily pursuits $[8,9]$.

Assessment of arm-hand function and performance is important in both clinical practice and research e.g. to determine the effectiveness of rehabilitation treatments and to monitor the progress of patients. In the present study, the term 'instrument' will refer to measurement instrument, i.e. instrument used to measure arm-hand function and/or performance.
Next to its intended use, the International Classification of Functioning, Disability and Health (ICF) framework [10] can be used for the classification of outcome measures. The ICF describes human functioning at three levels (Figure 1), i.e. function level (body structures and function), activity level (task execution) and participation level (involvement in life situations). Activity level is subdivided into capacity and performance. The term arm-hand skilled performance (AHSP) used throughout this study, refers to arm-hand function at the ICF activity level [11], including both capacity and performance.

In the last decades, the focus of rehabilitation on armhand disorders is slowly shifting from ICF function level towards activity and participation level [12], i.e. towards a level that is important to the patient, whose typical question is "What will I be able to do with my arm and hand in my daily pursuits once therapy has finished?". However, the relationship between function level and activity level is still poorly understood. A study by Arnould et al. showed a relation between hand impairment (function level) and manual ability (activity level) in children with $\mathrm{CP}$, but hand impairment predicted only $58 \%$ of the variability in manual ability measures [13]. Burridge et al. found significant correlations between several, though not all, measures at function level (e.g. active range of movement, and spasticity) and the Action Research Arm Test, a measure at activity level in patients with stroke [14].

Regarding activity level, it should be noted that outcomes of capacity measures and performance measures may differ strongly, since different constructs are measured, i.e. the highest level of functioning versus functioning in daily life

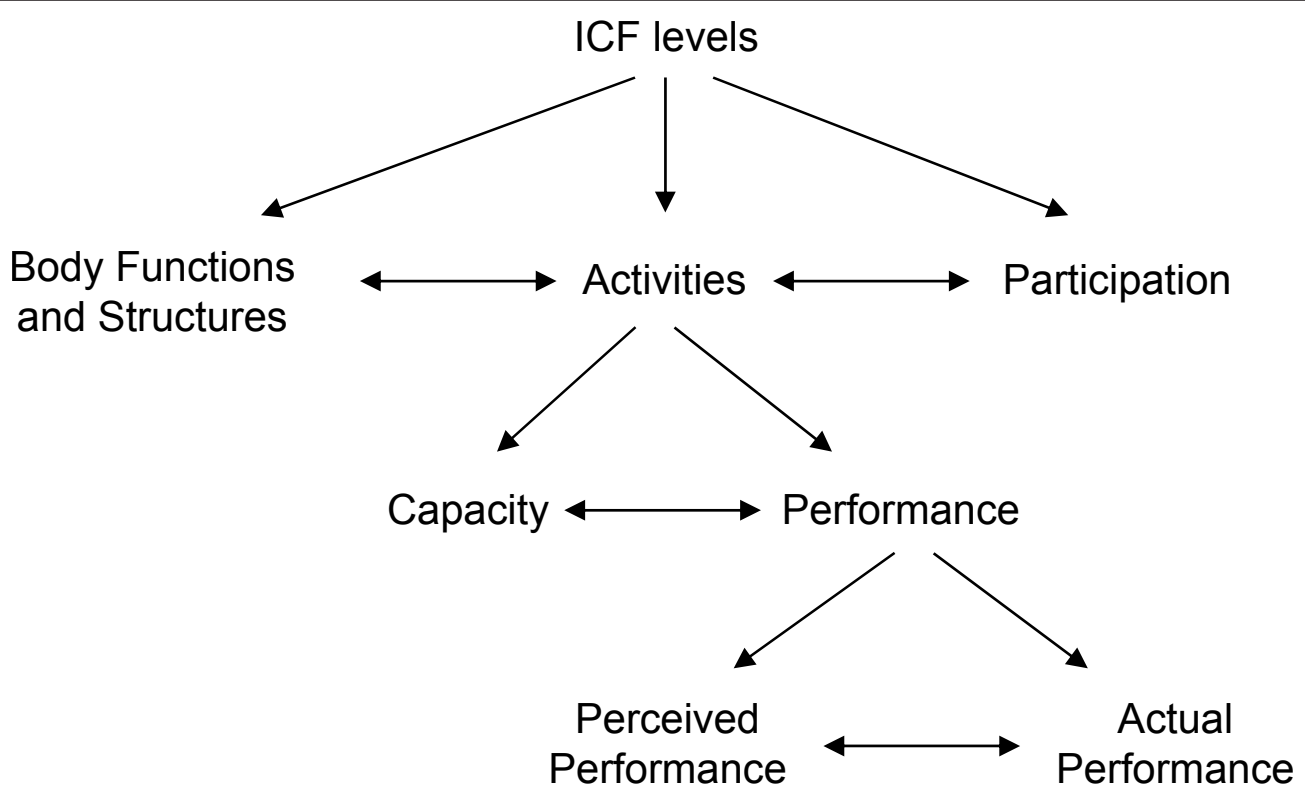

Figure 1 ICF levels and subdivision. 
situations. When assessing performance, like AHSP, two kinds of instruments are available. On the one hand, questionnaires can be used to measure perceived performance. On the other hand, actual performance can be measured by direct and objective assessment in the real-life situation.

For clinicians and researchers it is important to evaluate and compare the effects of therapies and treatments, in order to make a well-founded choice for the best therapy or treatment for the patient. This choice necessitates appropriate measurement instruments. Besides the differences in ICF levels and concepts (e.g. capacity or performance) instruments are quantifying, a large diversity in the content between instruments exists. To guide the choice of instruments, an overview of available instruments and their content is necessary. The aim of this systematic review is 1) to identify and evaluate the available instruments to assess AHSP in patients with stroke or CP and 2) to categorize the available instruments into the categories capacity, perceived performance and actual performance. Instruments for which no data about the validity and reliability was available were not included in this study.

\section{Methods}

This review consists of 5 steps: 1) A systematic literature search was performed to identify articles which included instruments assessing AHSP in patients with stroke or CP. 2) Articles were selected based on predetermined inclusion criteria. 3) All measurement instruments reported within the articles selected were extracted. 4) Only instruments that fitted a second set of predetermined inclusion criteria were kept. All other instruments were discarded. 5) The included instruments were further evaluated and classified, yielding a final set of instruments that is reported on.

\section{Step 1: systematic literature search}

A systematic search was performed to identify relevant articles published until November 2010, selected from the following databases: PubMed, CINAHL, EMBASE, Chochrane, PsychINFO, IEEE and Scopus. The search strategy consisted of 4 elements, focusing on 1) patient population; 2) upper extremity; 3) outcome domain and 4) measurement instrument. The combination of search terms used is listed in Table 1. Limits were set by using the terms 'human' and 'language: English, Dutch, German or French'.

\section{Step 2: article selection Inclusion and exclusion criteria}

Articles were included if they met all of the following inclusion criteria: 1) the article should include instruments developed for and/or used in patients with stroke or $\mathrm{CP} ; 2)$ the instrument used in the article should assess AHSP; 3) the article should be written in English, Dutch, German or French.

\section{Screening of abstracts}

All titles and abstracts of the articles retrieved from the literature search were divided among 4 reviewers and were screened for the inclusion and exclusion criteria. In cases where insufficient information was available from the title or the abstract, the full text of the article was examined. In cases of uncertainty, the title and abstract was screened by one of the other three reviewers. If it remained uncertain whether or not to include the article, the article was discussed between all 4 reviewers until consensus was reached. At the end of this step, a list of eligible articles was available.

\section{Definitions}

In this study several definitions have been used, adopted from the ICF [10]. In some cases ICF definitions were slightly adapted to adequately fit our needs in this review paper and to avoid misinterpretation. In literature, several terms and definitions exist to describe activities of daily living. No unambiguous definition exists to define basic ADL and extended ADL. Therefore, the definitions as described in Table 2 were formulated.

\section{Step 3: data extraction: identification of instruments}

The articles gathered from step 2 were analysed to identify instruments. Abstracts of these articles, and in case of insufficient information the full text, were screened to extract potential instruments. From several instruments more than one version was available. In such case, only

Table 1 Search strategy

\begin{tabular}{cl}
\hline Patient population & "Stroke" NOT "stroke volume" OR "cerebral palsy" OR "motor skill disorder" OR "hemiparesis" \\
\hline & AND \\
\hline Upper extremity & ("upper extremity" OR "upper limb" OR "arm" OR "hand" OR "wrist") NOT ("lower extremity" OR "lower limb") \\
\hline AND & ("motor activity" OR "activities of daily living" OR "motor skill" OR "motor skills" OR "function") NOT "gait" \\
\hline $\begin{array}{c}\text { Measurement } \\
\text { instrument }\end{array}$ & $\begin{array}{l}\text { ("Outcome assessment" OR "treatment outcome" OR "task performance and analysis" OR "evaluation studies as topics" OR } \\
\text { "disability evaluations" OR "rehabilitation" OR questionnaires" OR "ambulatory monitoring") NOT ("magnetic resonance } \\
\text { imaging" OR "blood" OR "cortex") }\end{array}$ \\
\hline
\end{tabular}


Table 2 Definitions

\begin{tabular}{|c|c|}
\hline Term & Definition \\
\hline Domain & $\begin{array}{l}\text { A domain is a practical and meaningful set of related physiological functions, anatomical structures, actions, tasks, or areas } \\
\text { of life. }\end{array}$ \\
\hline Activity level & The level of execution of meaningful tasks by an individual. \\
\hline Capacity & $\begin{array}{l}\text { The highest possible level of functioning of a person in a given domain at a given moment, measured in a standardized } \\
\text { environment. }\end{array}$ \\
\hline Perceived performance & $\begin{array}{l}\text { The level of functioning subjectively experienced by a person in a given domain at a given moment in his/her current } \\
\text { environment. }\end{array}$ \\
\hline Actual performance & $\begin{array}{l}\text { The objectively detectable level of functioning of a person in a given domain at a given moment in his/her current } \\
\text { environment. }\end{array}$ \\
\hline Amount of use & How often (frequency) or how much (quantity) the arm-hand is used. \\
\hline Quality of use & The quality with which the arm-hand is used during tasks or movements. \\
\hline Unimanual tasks & Tasks which are usually performed with one hand. \\
\hline Bimanual tasks & Tasks which are usually performed with both hands. \\
\hline $\begin{array}{l}\text { Activities of daily living } \\
\text { (ADL) }\end{array}$ & $\begin{array}{l}\text { Activities a person normally performs in daily life including activities performed for self-care, work, household activities and } \\
\text { leisure. }\end{array}$ \\
\hline Basic ADL & $\begin{array}{l}\text { Activities of daily living necessary to daily self-care, including personal hygiene, dressing, feeding, toileting, functional } \\
\text { transfers and mobility [15]. }\end{array}$ \\
\hline Extended ADL & $\begin{array}{l}\text { Activities of daily living, beyond basic ADL, related to home maintenance and required for independent living. For } \\
\text { example cleaning, cooking, doing laundry and shopping [15] }\end{array}$ \\
\hline Classification instrument & $\begin{array}{l}\text { Instrument used to describe upper limb performance on a level of categories, rather than to attribute scores that quantify } \\
\text { upper limb performance. }\end{array}$ \\
\hline
\end{tabular}

1 version of the instrument was included in this systematic review. The version which was tested on its validity and reliability in the target population and most often used was chosen.

\section{Step 4: inclusion of instruments}

All instruments retrieved from step 3 were screened by 1 reviewer on the following inclusion and exclusion criteria. Inclusion criteria: 1) instrument assesses AHSP; 2) instrument has to be reported valid and reliable in the target population (stroke and/or CP). Exclusion criteria: 1) instrument is a classification instrument; 2) measuring AHSP is not the main goal of the instrument; 3 ) instrument is not uniquely used to asses AHSP.

Information about the properties and content of the instruments, necessary to apply the inclusion and exclusion criteria, were retrieved from several sources, i.e. from: 1 ) the articles included after the second step; 2) a new search on database Pubmed, using the name of the instrument (in combination with the following terms: 'valid' OR 'validity' OR 'reliable' OR 'reliability' OR 'responsive' OR 'responsiveness'); 3) other internet sources such as databases of instruments; 4) contact with authors describing the instruments. After this step, a final list of included instruments was composed.

\section{Step 5: classification and evaluation of instruments}

The instruments from the final list were classified into the following categories: capacity, perceived performance and actual performance, based on the definitions presented earlier. In case of uncertainty about the classification, the instrument was discussed among the 4 reviewers, who are also experts in the field of arm-hand rehabilitation, until consensus was reached. The following information about each instrument was examined: target population, total number of items included in the test, number of items concerning measurement of the upper extremity, ICF levels measured with the instrument, inclusion of unimanual and/or bimanual items, assessment of amount of use and/or quality of use and the responsiveness.

\section{Results}

The systematic literature search (step 1) resulted in a total of 2216 articles, of which 747 were included after step 2 . A total of 188 measurement instruments were identified from these articles (step 3) of which 30 were included (step 4), and further evaluated (step 5). A flowchart depicting this process is presented in Figure 2.

In Tables 3, 4 and 5 the instruments included in the categories capacity, perceived performance and actual performance are described, including information about the content of the instruments. Table 6 summarizes the number of instruments related to capacity, perceived performance and actual performance and the number and percentage of instruments per characteristic (e.g. target population, ICF level(s) measured, unimanual and/or bimanual tasks included, etc.).

The most noticeable difference is the number of instruments included per category. In the categories capacity 


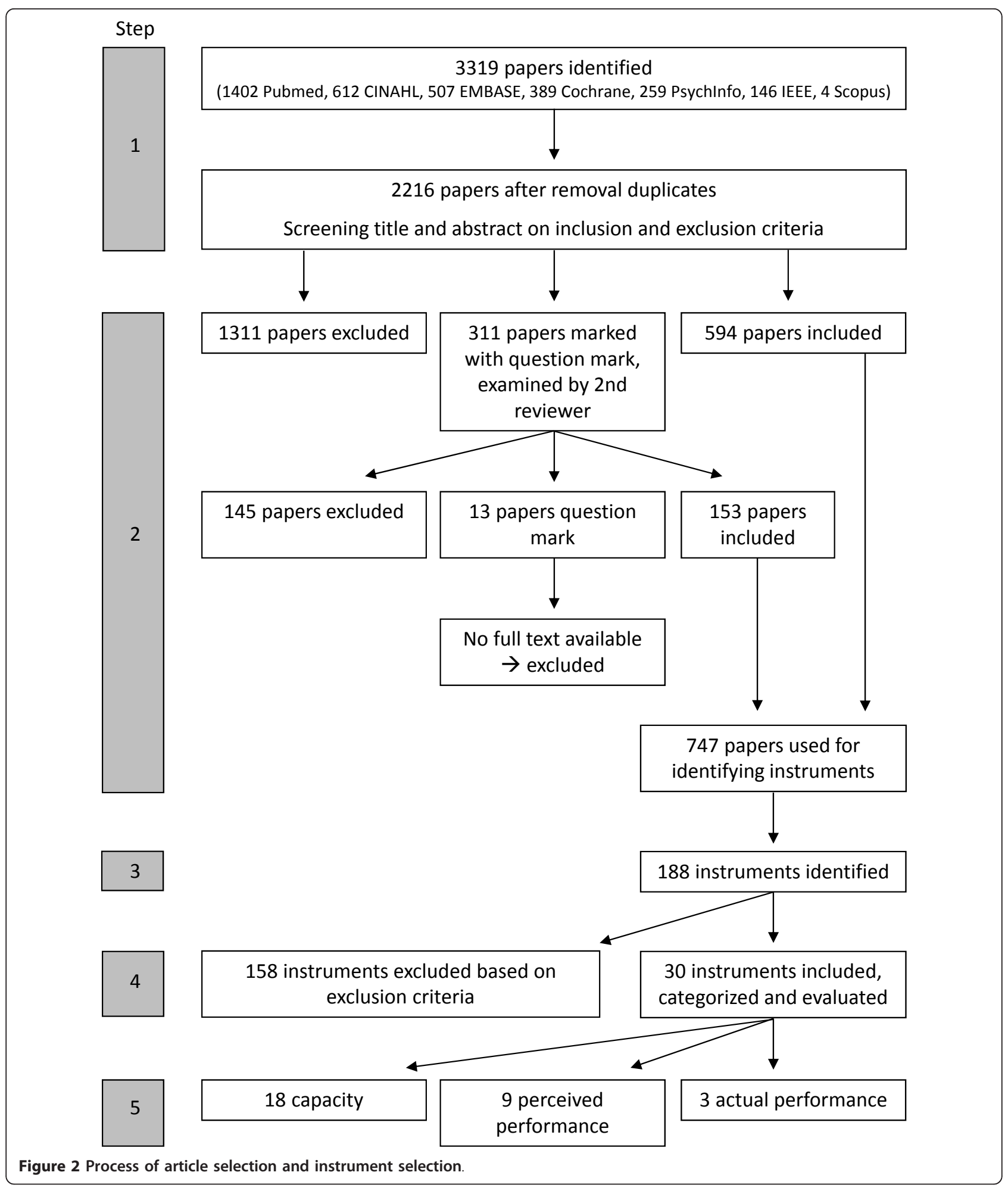

and perceived performance, 18 and 9 instruments were included respectively, whereas only 3 instruments were categorized as measuring actual performance. In addition, more instruments are available for patients with stroke compared to patients with $\mathrm{CP}$, with only $10 \%$ of the instruments used and tested for their psychometric properties in both patients groups. For 2 instruments, two versions exist, one for adults and one for children. 
Table 3 Instruments assessing capacity

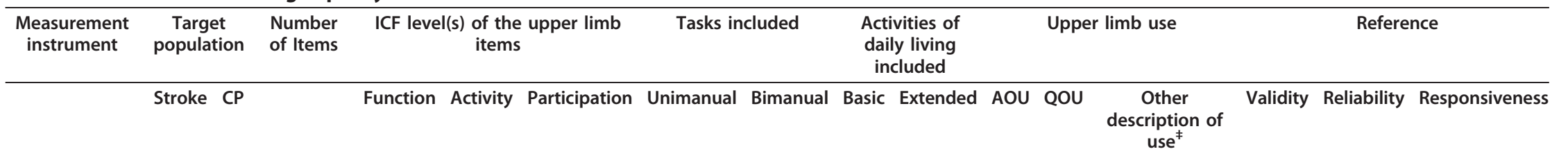

\begin{tabular}{|c|c|c|c|c|c|c|c|c|c|c|c|c|c|c|c|}
\hline & \multicolumn{15}{|c|}{ Instruments including only items at ICF activity level } \\
\hline $\begin{array}{c}\text { ADL observation } \\
{[16]}\end{array}$ & $\sqrt{ }$ & & 4 & & $\sqrt{ }$ & $(\sqrt{ })^{*}$ & $\sqrt{ }$ & $\sqrt{ }$ & $(\sqrt{ })^{*}$ & & & $\sqrt{ }$ & {$[16]$} & [16] & \\
\hline AMAT [17] & $\sqrt{ }$ & & 13 & & $\sqrt{ }$ & $\sqrt{ }$ & $\sqrt{ }$ & $\sqrt{ }$ & $\sqrt{ }$ & & $\sqrt{ }$ & $\sqrt{ }$ & {$[17]$} & {$[17]$} & {$[17]$} \\
\hline AMPS [15] & $\sqrt{ }$ & $\sqrt{ }$ & 2 & & $\sqrt{ }$ & & $\sqrt{ }$ & $\sqrt{ }^{*}$ & $\sqrt{ }{ }^{*}$ & & $\sqrt{ }$ & & {$[15]$} & {$[15]$} & \\
\hline CAHAI [18] & $\sqrt{ }$ & & 13 & & $\sqrt{ }$ & & $\sqrt{ }$ & $\sqrt{ }$ & $\sqrt{ }$ & & & $\sqrt{ }$ & [19] & {$[19]$} & [19] \\
\hline FAT [20] & $\sqrt{ }$ & & 5 & & $\sqrt{ }$ & $\sqrt{ }$ & $\sqrt{ }$ & $\sqrt{ }$ & $\sqrt{ }$ & & & $\sqrt{ }$ & [20] & {$[20]$} & {$[21]$} \\
\hline TEMPA [22] & $\sqrt{ }$ & & 9 & & $\sqrt{ }$ & $\sqrt{ }$ & $\sqrt{ }$ & $\sqrt{ }$ & $\sqrt{ }$ & & $\sqrt{ }$ & $\sqrt{ }$ & [23] & [22] & \\
\hline UBDS [24] & $\sqrt{ }$ & & 1 & & $\sqrt{ }$ & & $\sqrt{ }$ & $\sqrt{ }$ & & & & $\sqrt{ }$ & [24] & [24] & [24] \\
\hline \multirow[t]{2}{*}{ VOAA-DDD [25] } & . & $\sqrt{ }$ & 2 & & $\sqrt{ }$ & & $\sqrt{ }$ & & $\sqrt{ }$ & $\sqrt{ }$ & & $\sqrt{ }$ & [26] & [26] & \\
\hline & \multicolumn{15}{|c|}{ Instruments combining items at ICF activity level with items at ICF function level } \\
\hline AAUT [27] & $\sqrt{ }$ & & 17 & $\sqrt{ }$ & $\sqrt{ }$ & $\sqrt{ }$ & $\sqrt{ }$ & & $\sqrt{ }$ & $\sqrt{ }$ & $\sqrt{ }$ & & [27] & [27] & \\
\hline ARAT [28] & $\sqrt{ }$ & & 19 & $\sqrt{ }$ & $\sqrt{ }$ & $\sqrt{ }$ & & & $\sqrt{ }$ & & $\sqrt{ }$ & & [28] & {$[28]$} & {$[28]$} \\
\hline FTHUE [29] & $\sqrt{ }$ & & 17 & $\sqrt{ }$ & $\sqrt{ }$ & $\sqrt{ }$ & $\sqrt{ }$ & & $\sqrt{ }$ & & & $\sqrt{ }$ & [29] & [29] & \\
\hline JTHFT [30] & $\sqrt{ }$ & & 7 & $\sqrt{ }$ & $\sqrt{ }$ & $\sqrt{ }$ & & $\sqrt{ }$ & $\sqrt{ }$ & & & $\sqrt{ }$ & [31] & [31] & [32] \\
\hline Melbourne [33] & & $\sqrt{ }$ & 16 & $\sqrt{ }$ & $\sqrt{ }$ & $\sqrt{ }$ & & $\sqrt{ }$ & $\sqrt{ }$ & & $\sqrt{ }$ & & [33] & [34] & \\
\hline MESUPES [35] & $\sqrt{ }$ & & 17 & $\sqrt{ }$ & $\sqrt{ }$ & $\sqrt{ }$ & & & $\sqrt{ }$ & & $\sqrt{ }$ & $\sqrt{ }$ & [35] & [35] & \\
\hline MFT [36] & $\sqrt{ }$ & & 8 & $\sqrt{ }$ & $\sqrt{ }$ & $\sqrt{ }$ & & & $\sqrt{ }$ & & & $\sqrt{ }$ & {$[37]$} & {$[37]$} & \\
\hline QUEST [38] & & $\sqrt{ }$ & 36 & $\sqrt{ }$ & $\sqrt{ }$ & $\sqrt{ }$ & $\sqrt{ }$ & $\sqrt{ }$ & $\sqrt{ }$ & & & $\sqrt{ }$ & [38] & [38] & \\
\hline SHUEE [39] & & $\sqrt{ }$ & 40 & $\sqrt{ }$ & $\sqrt{ }$ & $\sqrt{ }$ & $\sqrt{ }$ & $\sqrt{ }$ & $\sqrt{ }$ & $\sqrt{ }$ & & $\sqrt{ }$ & [39] & [39] & \\
\hline WMFT [40] & $\sqrt{ }$ & & 17 & $\sqrt{ }$ & $\sqrt{ }$ & $\sqrt{ }$ & & & $\sqrt{ }$ & & & $\sqrt{ }$ & [41] & [41] & [41] \\
\hline
\end{tabular}

\# = This subcategory covers answers like "can be performed (yes/no)" or "independent performance (yes/no/partly)"; or descriptive answers like "How much feedback does the patient require to complete the task?". $*$ item can be chosen by therapist/patient and can therefore be unimanual or bimanual and basic ADL or extended ADL.

$\mathrm{CP}=$ cerebral palsy; $\mathrm{AOU}=$ amount of use; $\mathrm{QOU}=$ quality of use.

AAUT = Actual Amount of Use Test; ADL observation = Activities of Daily Living observation; AMAT $=$ Arm Motor Ability Test; AMPS = Assessment of Motor and Process Skills; ARAT = Action Research Arm Test; CAHAI = Chedoke Arm Hand Actvity Inventory; FAT = Frenchay Arm Test; FTHUE = Functional Test for the Hemiplegic Upper Extremity; JTHFT = Jebsen-Taylor Hand Function Test; LMAS = Lindmark Motor

Assessment Scale; Melbourne = Melbourne Assessment of Unilateral Upper Limb Function; MESUPES = Motor Evaluation Scale for Upper Extremity Stroke Patients; MFT = Manual Function Test; QUEST = Quality of Upper extremity Skills Test; SHUEE = Shriners Hospital for Children Upper Extremity Evaluation; TEMPA = Upper Extremity Performance Test for Elderly (Test d'Evaluation des Membres supérieurs de Personnes Agées); UBDS = Upper Body Dressing Scale; VOAA-DDD = Video Observation Aarts and Aarts - DDD; WMFT = Wolf Motor Function Test 
Table 4 Instruments assessing perceived performance

\begin{tabular}{|c|c|c|c|c|c|c|c|c|c|c|c|c|c|c|c|}
\hline \multirow[t]{2}{*}{$\begin{array}{l}\text { Measurement } \\
\text { instrument }\end{array}$} & \multicolumn{2}{|c|}{$\begin{array}{c}\text { Target } \\
\text { population }\end{array}$} & \multirow[t]{2}{*}{$\begin{array}{l}\text { Number } \\
\text { of Items }\end{array}$} & \multicolumn{2}{|c|}{$\begin{array}{l}\text { ICF level(s) of the upper limb } \\
\text { items }\end{array}$} & \multicolumn{2}{|c|}{ Tasks included } & \multicolumn{2}{|c|}{$\begin{array}{l}\text { Activities of } \\
\text { daily living } \\
\text { included }\end{array}$} & \multicolumn{3}{|c|}{ Upper limb use } & \multicolumn{3}{|c|}{ Reference } \\
\hline & Stroke & $\mathrm{CP}$ & & Function & Activity Participation & Unimanual & Bimanual & Basic & Extended & AOU & QOU & $\begin{array}{c}\text { Other } \\
\text { description of } \\
\text { use }^{\ddagger}\end{array}$ & Validity & Reliability & Responsiveness \\
\hline & \multicolumn{15}{|c|}{ Instruments including only items at ICF activity level } \\
\hline Abilhand [42] & $\sqrt{ }$ & & 23 & & $\sqrt{ }$ & $\sqrt{ }$ & $\sqrt{ }$ & $\sqrt{ }$ & $\sqrt{ }$ & & & $\sqrt{ }$ & [43] & [43] & \\
\hline $\begin{array}{l}\text { Abilhand-kids } \\
\text { [44] }\end{array}$ & & $\sqrt{ }$ & 21 & & $\sqrt{ }$ & $\sqrt{ }$ & $\sqrt{ }$ & $\sqrt{ }$ & $\sqrt{ }$ & & & $\sqrt{ }$ & [44] & [44] & \\
\hline COPM [45] & $\sqrt{ }$ & $\sqrt{ }$ & variable & & $\sqrt{ }$ & $\sqrt{*}$ & $\sqrt{*}$ & $\sqrt{ }{ }^{*}$ & $\sqrt{*}$ & & & $\sqrt{ }$ & {$[46,47]$} & {$[46,47]$} & {$[47,48]$} \\
\hline DHI [49] & $\sqrt{ }$ & & 18 & & $\sqrt{ }$ & $\sqrt{ }$ & $\sqrt{ }$ & $\sqrt{ }$ & $\sqrt{ }$ & & & $\sqrt{ }$ & [49] & [49] & [49] \\
\hline GAS [50] & $\sqrt{ }$ & $\sqrt{ }$ & variable & & $\sqrt{ }$ & $\sqrt{ }^{*}$ & $\sqrt{ }^{*}$ & $\sqrt{ } \sqrt{*}^{*}$ & $\sqrt{ }^{*}$ & & & $\sqrt{ }$ & {$[51,52]$} & {$[51,52]$} & {$[51,52]$} \\
\hline HFS [53] & $\sqrt{ }$ & & 13 & & $\sqrt{ }$ & $\sqrt{ }$ & $\sqrt{ }$ & $\sqrt{ }$ & $\sqrt{ }$ & & & $\sqrt{ }$ & [53] & [53] & \\
\hline MAL [54] & $\sqrt{ }$ & & 26 & & $\sqrt{ }$ & $\sqrt{ }$ & $\sqrt{ }$ & $\sqrt{ }$ & $\sqrt{ }$ & $\sqrt{ }$ & $\sqrt{ }$ & & [54] & [54] & [54] \\
\hline \multirow[t]{2}{*}{ pMAL [55] } & & $\sqrt{ }$ & 22 & & $\sqrt{ }$ & $\sqrt{ }$ & $\sqrt{ }$ & $\sqrt{ }$ & $\sqrt{ }$ & $\sqrt{ }$ & $\sqrt{ }$ & & [56] & {$[56]$} & \\
\hline & \multicolumn{15}{|c|}{ Instruments combining items at ICF activity level with items at ICF function level } \\
\hline $\begin{array}{l}\text { UE Item Bank } \\
\text { [57] }\end{array}$ & & $\sqrt{ }$ & 49 & $\sqrt{ }$ & $\sqrt{ }$ & $\sqrt{ }$ & $\sqrt{ }$ & $\sqrt{ }$ & $\sqrt{ }$ & & & $\sqrt{ }$ & {$[58,59]$} & [58] & \\
\hline
\end{tabular}

$$
\text { [57] }
$$

\#= This subcategory covers answers like "can be performed (yes/no)" or "independent performance (yes/no/partly)"; or descriptive answers like "How much effort does it take to perform the task?". * $=$ item can be chosen by therapist/patient and can therefore be unimanual or bimanual and basic ADL or extended ADL

$\mathrm{CP}=$ cerebral palsy; $\mathrm{AOU}=$ amount of use; $\mathrm{QOU}=$ quality of use.

COPM = Canadian Occupational Performance Measure; DHI = Duruoz Hand Index; GAS = Goal Attainment Scaling; HFS = Hand Function Survey, MAL = Motor Activity Log; pMAL = Pediatric Motor Activity Log; UE Item bank = upper extremity item bank 


\section{Table 5 Instruments assessing actual performance}

\begin{tabular}{|c|c|c|c|c|c|c|c|c|c|c|c|c|c|c|c|c|}
\hline \multirow[t]{2}{*}{$\begin{array}{l}\text { Measurement } \\
\text { instrument }\end{array}$} & \multicolumn{2}{|c|}{$\begin{array}{c}\text { Target } \\
\text { population }\end{array}$} & \multirow[t]{2}{*}{$\begin{array}{l}\text { Number } \\
\text { of items }\end{array}$} & \multicolumn{3}{|c|}{$\begin{array}{l}\text { ICF level(s) of the upper limb } \\
\text { items }\end{array}$} & \multicolumn{2}{|c|}{ Tasks included } & \multicolumn{2}{|c|}{$\begin{array}{l}\text { Activities of } \\
\text { daily living } \\
\text { included }\end{array}$} & \multicolumn{3}{|c|}{ Upper limb use } & \multicolumn{3}{|c|}{ Reference } \\
\hline & Stroke & $\mathrm{CP}$ & & Function & Activity & Participation & Unimanual & Bimanual & Basic & Extended & AOU & QOU & $\begin{array}{c}\text { Other } \\
\text { description of } \\
\text { use }^{\ddagger}\end{array}$ & Validity & Reliability & Responsiveness \\
\hline $\begin{array}{l}\text { Accelerometry } \\
{[60]}\end{array}$ & $\sqrt{ }$ & & Variable & & $\sqrt{ }$ & & $\sqrt{ }$ & $\sqrt{ }$ & $\sqrt{ }$ & $\sqrt{ }$ & $\sqrt{ }$ & & & [60] & [60] & \\
\hline AHA [61] & & $\sqrt{ }$ & Variable & & $\sqrt{ }$ & & $\sqrt{ }$ & $\sqrt{ }$ & & $\sqrt{ }$ & & $\sqrt{ }$ & & [62] & {$[62]$} & {$[62]$} \\
\hline FAABOS [63] & $\sqrt{ }$ & & Variable & & $\sqrt{ }$ & & $\sqrt{ }$ & $\sqrt{ }$ & $\sqrt{ }$ & $\sqrt{ }$ & $\sqrt{ }$ & & & [63] & [63] & \\
\hline
\end{tabular}

$\neq=$ This subcategory covers answers like "can be performed (yes/no)" or "independent performance (yes/no/partly)"; or descriptive answers like "How much effort does it take to perform the task?". $\mathrm{CP}=$ cerebral palsy; $\mathrm{AOU}=$ amount of use; $\mathrm{QOU}=$ quality of use.

$\mathrm{AHA}=$ Assisting Hand Assessment; FAABOS = Functional Arm Activity Behavioral Observation System 
Table 6 Overview of the number and percentage of instruments for different characteristics, presented per category

\begin{tabular}{|c|c|c|c|c|c|c|}
\hline & \multicolumn{2}{|c|}{ Capacity } & \multicolumn{2}{|c|}{ Perceived performance } & \multicolumn{2}{|c|}{ Actual performance } \\
\hline & number & $\%$ & number & $\%$ & number & $\%$ \\
\hline Total number measurement instruments & 18 & 100 & 9 & 100 & 3 & 100 \\
\hline \multicolumn{7}{|l|}{ Target population } \\
\hline Stroke patients only & 13 & $72.2 \%$ & 4 & $44.4 \%$ & 2 & $67 \%$ \\
\hline CP patients only & 4 & $22.2 \%$ & 3 & $33.3 \%$ & 1 & $33 \%$ \\
\hline Stroke and $C P$ & 1 & $5.6 \%$ & 2 & $22.2 \%$ & 0 & $0 \%$ \\
\hline \multicolumn{7}{|l|}{ ICF level } \\
\hline Activity level only & 8 & $44.4 \%$ & 8 & $88.9 \%$ & 3 & $100 \%$ \\
\hline Activity \& function level & 10 & $55.6 \%$ & 1 & $11.1 \%$ & 0 & $0 \%$ \\
\hline Activity \& participation level & 0 & $0 \%$ & 0 & $0 \%$ & 0 & $0 \%$ \\
\hline Activity, function \& participation level & 0 & $0 \%$ & 0 & $0 \%$ & 0 & $0 \%$ \\
\hline \multicolumn{7}{|l|}{ Task included } \\
\hline Unimanual only & 6 & $33.3 \%$ & 0 & $0 \%$ & 0 & $0 \%$ \\
\hline Bimanual only & 4 & $22.2 \%$ & 0 & $0 \%$ & 0 & $0 \%$ \\
\hline Unimanual \& bimanual & 8 & $44.4 \%$ & 9 & $100 \%$ & 3 & $100 \%$ \\
\hline \multicolumn{7}{|l|}{ Activities of daily living included } \\
\hline Basic ADL only & 1 & $5.6 \%$ & 0 & $0 \%$ & 0 & $0 \%$ \\
\hline Extended ADL only & 7 & $38.9 \%$ & 0 & $0 \%$ & 1 & $33 \%$ \\
\hline Both basic and extended ADL & 10 & $55.6 \%$ & 9 & $100 \%$ & 2 & $67 \%$ \\
\hline \multicolumn{7}{|l|}{ Upper limb use } \\
\hline AOU only & 0 & $0 \%$ & 0 & $0 \%$ & 2 & $67 \%$ \\
\hline QOU only & 3 & $16.7 \%$ & 0 & $0 \%$ & 1 & $33 \%$ \\
\hline Other description of use only & 9 & $50 \%$ & 7 & $77.8 \%$ & 0 & $0 \%$ \\
\hline Combination of $\mathrm{AOU}$ and $\mathrm{QOU}$ & 1 & $5.6 \%$ & 2 & $22.2 \%$ & 0 & $0 \%$ \\
\hline Combination of $\mathrm{AOU}$ and other description of use & 2 & $11.1 \%$ & 0 & $0 \%$ & 0 & $0 \%$ \\
\hline Combination of QOU and other description of use & 3 & $16.7 \%$ & 0 & $0 \%$ & 0 & $0 \%$ \\
\hline \multicolumn{7}{|l|}{ Psychometric property } \\
\hline Responsiveness tested & 7 & $38.8 \%$ & 4 & $44.4 \%$ & 1 & $33 \%$ \\
\hline Responsiveness not tested & 11 & $61.1 \%$ & 5 & $55.6 \%$ & 2 & $67 \%$ \\
\hline
\end{tabular}

$\mathrm{CP}=$ cerebral palsy; $\mathrm{AOU}=$ amount of use; $\mathrm{QOU}=$ quality of use; $\mathrm{ADL}=$ activities of daily living

In the category capacity, about half of the instruments solely measure at ICF activity level. The other half of the instruments also measure at function level. In the category perceived performance almost $90 \%$ of the instruments solely measure at ICF activity level, whereas all instruments in the category actual performance measure only at ICF activity level.

In the category capacity, instruments consist of unimanual or bimanual items, or a combination of unimanual and bimanual items. In the category perceived performance, all instruments include both unimanual and bimanual items. In daily life, measured with instruments for actual performance, both unimanual and bimanual tasks are present. Most instruments include a combination of basic activities of daily living and extended activities of daily living.

Only a few instruments in the categories capacity and perceived performance measure quality of use (QOU), whereas no instruments measure the amount of use
(AOU). Most instruments use another description to measure upper limb use for example how much assistance does the patient need to perform the task. Instruments assessing actual performance measure mostly AOU, but the Assisting Hand Aassessment (AHA) measures QOU of the affected arm-hand. For about half of all measurement instruments that were reported to be valid and reliable, responsiveness was also tested in the target population.

\section{Discussion}

\section{Main findings}

A total of 30 instruments were included in this review, 18 of which measure capacity, 9 measure perceived performance and 3 measure actual performance.

Even though stroke patients and cerebral palsy (CP) patients share most of their clinical symptoms, almost all of the upper extremity outcome measures are developed 
for, tested in and used in only one patient population, i.e. either stroke or CP. To gain more insight in the possibilities of common therapies, transcending diagnosis boundaries, agreement about the choice of common instruments is needed.

Regarding stroke or CP rehabilitation, many instruments are available in the categories capacity and perceived performance. However, instruments assessing actual performance are less abundantly available for these patients. This is in sharp contrast to the importance that patients, clinicians and researchers in the field of stroke and CP rehabilitation attribute to high quality arm-hand skilled performance (AHSP) in real life.

For capacity and perceived performance only a few instruments assess quality of use (QOU) of the affected arm and hand, whereas no instruments assess the amount of use (AOU). Many instruments use other descriptions of upper limb use, such as "how much assistance is needed to perform the task?".

In addition, this systematic review revealed that a large diversity in the content of the instruments exists, making it more difficult to compare different outcome measures with each other.

\section{Agreement about the choice and use of instruments}

It can be concluded that a wide range of measurement instruments for the categories capacity and perceived performance exists. This systematic review identified 30 instruments currently available to assess AHSP in patients with stroke or $\mathrm{CP}$, which are reported to be both valid and reliable. More than 155 instruments were excluded, mainly because no information was published about the psychometric properties in patients with stroke or CP. Other reasons for exclusion were for example "instrument does not include items to assess the upper extremity" and "instrument is a classification instrument". Nineteen instruments were excluded because next to arm-hand items, they contain also items not related to the upper extremity. Although instruments containing only arm-hand items are used most and are most appropriate to assess arm hand performance, the abovementioned nineteen instruments that were excluded might also be of interest in arm-hand assessment. For the sake of completeness, these instruments are listed in table 8 in the Additional file 1. The responsiveness has not been tested in about $60 \%$ of the instruments included in this review.

The chance of consistent use of outcome measures between studies decreases as the range of available instruments increases. The use of different outcome measures makes it more difficult to compare similar studies with each other. It is very important that a future agreement about the choice and the use of common instruments is achieved. This may facilitate comparison between studies, may result in more powerful meta-analyses, and enables the use of published data for group size calculations for new studies [64].

This systematic review demonstrated that only 3 out of 30 instruments were used in both patients with stroke and patients with CP (i.e. Assessment of Motor and Process Skills [15], the Goal Attainment Scale [50] and the Canadian Occupational Performance Measure [45]). In addition, for 2 instruments separate versions exist for adults and children (i.e. for the MAL/pMAL and the Abilhand/Abilhand-kids). Differences are for example age-dependent item content. Dobkin stated that the mechanisms of motor control, cognitive control and neural adaptation that accompany training and learning are not as much dependent on the underlying disease as on the spared nodes within neural networks [1]. Indeed it is seen that clinical practice paradigms to improve for instance arm-hand function do not tend to differ much between patient populations [1]. To gain more insight in the possibilities of common therapies for different patient populations with similar clinical characteristics, it is important that the same outcome measures are used. Only then a good comparison between studies assessing the same therapies, applied in different patient populations is possible and worthwhile.

It is important to investigate whether the outcome measure which can be used in several patient populations, is valid, reliable and responsive in each of the populations it is used in. One reason is that the course of improvement of AHSP, during and after rehabilitation, may differ between patient populations. Caused by, for example, the fact that stroke patients can rely on learned motor patterns which they have developed during their life, whereas in children with $\mathrm{CP}$ these motor patterns may not be present.

\section{Capacity and perceived performance}

For the category capacity about 6 times more instruments are available than for the capacity actual performance. For the category perceived performance 3 times as many instruments are available.

Although information about the highest level of functioning (capacity) may be very useful, it does not reveal valid information about the functioning of a patient in daily life (performance). It is known that a large difference may exist between capacity and performance. This difference may be caused, among others, by the learned non-use phenomenon [27], developmental disregard [65], changes in the role of the patient at home and in the society [3] and the fact that capacity measures the highest possible level of functioning during a short period of time (i.e. time of testing) [10]. The latter does not mimic real life situations, where performance is continuous and, for instance, fatigue plays a role. 
Patients, clinicians and researchers may have questions on both aspects of AHSP: capacity and performance. Depending on the information needed, the outcome measure should be chosen accordingly.

For the assessment of performance in stroke and CP, most instruments currently available evaluate perceived performance, whereas only 3 instruments assess actual performance. The questionnaires used to assess perceived performance take the perspective of the patient into account, which may be desirable but also has disadvantages. These questionnaires rely on recall and valid reporting of the patient. The cognitive problems stroke patients may have might influence the recall. In addition, the Hawthorn effect may play a role, i.e. the overestimation of arm-hand performance by the patient because his/her desire to improve or to please the examiner [66]. Furthermore, many children with $\mathrm{CP}$ are not able to fill in the questionnaire themselves and have to rely on parents and caregivers to fill in the questionnaire, leading to a different perspective, which may render the questionnaire invalid.

\section{Actual performance}

Capacity and perceived performance are both relevant for the assessment of AHSP, but actual performance should equally be taken into account, since this reflects the real functioning of a patient in daily life. Actual performance is measured objectively. One example is video observation, in which the performance of a patient is unobtrusively monitored, while performing activities of daily living. A disadvantage of video observation is that the video material has to be assessed by (multiple) experts, which makes this method potentially subjective and very time consuming. Other disadvantages are the possible intrusion on the patient's privacy and the problems of installing the system in a patient's home.

Although the video-based AHA instrument is not applied in the home situation, it was classified as a measure for actual performance, because the spontaneous use of the affected arm during a 15 minutes free play is determined using video observation.

Another method to assess actual performance is accelerometry, measuring the actual AOU of the arm-hand in daily life. Wearing accelerometers is unobtrusive and data can be collected for several consecutive days. Because data collection is done during the whole day, the registered activity will include specific task-related movements, but also non-functional movements and unintentional arm activity. Accelerometry does not provide information about the QOU of the affected arm-hand. The latter is especially of interest for patients, clinicians and researchers. The QOU of the affected arm and hand is associated with the ability to use the affected arm and hand in the home situation, performing activities of daily living.
Currently several promising new instruments to assess actual performance have not yet been tested as to their psychometric properties and were therefore not included in this systematic review. Two examples of such instruments are the Strathclyde Upper Limb Activity Monitor (SULAM) [67] and the Stroke Upper Limb Activity Monitor (Stroke-ULAM) [68]. The SULAM uses a pressure transducer and electrohydraulic activity sensor to determine the vertical replacement of the wrist compared to the shoulder. The Stroke-ULAM consists of 5 accelerometers and 2 electrogoniometers, measuring the actual upper limb usage of both limbs and the percentage of activity of the affected limb compared to the unaffected limb.

In order to assess actual performance in stroke and $\mathrm{CP}$, it is important that the systems under development will be tested more extensively to determine their utility and psychometric properties in both patient populations. In addition, measurement instruments for the assessment of actual performance have to be (further) developed, assessing also other aspects of AHSP such as QOU or information about the type of activity performed. Considering the importance of instruments transcending diagnosis boundaries, such instruments should be able to be used in different patient populations.

\section{Content of the instruments}

A large diversity in the content of the instruments to assess AHSP in patients with stroke or CP exists. About half of the instruments included in the category capacity, solely measure at ICF activity level, whereas the other half of the instruments cover more ICF levels. About 89\% of the instruments included in the category perceived performance and $100 \%$ of the instruments in the category actual performance solely measure at ICF activity level. If the aim of the study is to measure on ICF activity level, instruments assessing solely on ICF activity level are to be preferred. Whenever more ICF levels are included, the interpretation of the results becomes more difficult, especially when the outcome exists of a total score covering the different ICF levels.

The inclusion of unimanual and/or bimanual items differs among instruments. To determine the capacity of the affected arm-hand, unimanual tasks are useful because these tasks force the use of the affected arm-hand, which can be assessed. However, in daily life, many tasks are bimanual requiring both hands to perform the tasks. Moreover in daily life, the affected arm-hand is rarely used for unimanual tasks [69]. Therefore, if assessment of AHSP in daily life is aimed for, bimanual items should be included.

Although there are some differences in the inclusion of basic and/or extended activities of daily living, the majority of the instruments included both basic and extended activities of daily living. 


\section{Considerations}

Some considerations can be made regarding this systematic review. Based on the definitions stated earlier, some instruments which, in other studies, were classified as activity measures, were excluded in this systematic review, for example the nine hole peg test and box and block test [70]. However, the definitions were formulated in order to make a distinction between instruments including tasks which are meaningful in daily life and tasks which are not meaningful in daily life. Instruments containing activities of daily living in the items, but measure on function level (e.g. kinematics) were also excluded.

Instruments used as classification instruments rather than assessment tools for AHSP were excluded. Examples of such instruments are the Manual Ability Classification Instrument (MACS) [71] and the House classification [72].

Some instruments, such as the COPM and the GAS can be used to assess individual goals of patients. These instruments can be used to assess AHSP (whenever the individual goals are arm-hand activities) and have been demonstrated to be valuable in the assessment of AHSP [73]. Therefore, these instruments were included in this review, in contrast to other reviews $[69,74]$. This gives a more complete overview, of all instruments available. Moreover, individual goal setting instruments are valuable since they reflect the improvement of AHSP on the tasks which are most important for the patient.

\section{Limitations}

This systematic review has some limitations that have to be addressed. One limitation might be the fact that the articles retrieved from the search strategy were divided among four reviewers. However, strict a priori rules were applied in the selection and evaluation of articles and instruments, and in case of even the slightest doubt, the article was reviewed by another reviewer and if needed discussed among all four reviewers.

A second limitation might be that in this systematic review, instruments were included whenever they were reported to be valid and reliable. No criteria were applied to determine the methodological quality of the studies describing the psychometrics. However, the aim of this review was to identify and evaluate instruments available for assessing AHSP in patients with stroke or $\mathrm{CP}$, rather than to give an extended overview of the psychometric properties of these instruments. The latter one is an important next step.

\section{Conclusions}

This systematic review provides an overview of available instruments to assess AHSP in patients with stroke and patients with $\mathrm{CP}$. This overview may be used as a guide for instrument selection.
Currently, a limited number of valid and reliable instruments assessing actual performance for patients with stroke or CP are available. Furthermore, the 3 instruments available do not cover all domains interesting for AHSP. In order to assess actual performance, existing tools have to be adapted and new tools have to be developed, which will be applicable in more than one patient population. In addition, quantifying the QOU of the affected arm-hand should be taken into account while assessing activities of daily living.

Furthermore, only a few instruments are applicable for both patients with stroke and patients with CP. To better compare studies, and to gain more insight in the possibilities of common therapies for different patient populations with similar clinical characteristics, consensus should be reached regarding the choice and use of outcome measures which can be used in different patient populations.

\section{Funding}

This paper was funded by Adelante, Centre of Expertise in Rehabilitation and Audiology, Hoensbroek, the Netherlands.

\section{Additional material}

Additional file 1: Excluded instruments [75-203]

\section{Author details}

${ }^{1}$ Research School CAPHRI, Department of Rehabilitation Medicine, Maastricht University, Maastricht, the Netherlands. ${ }^{2}$ Adelante, Centre of Expertise in Rehabilitation and Audiology, Hoensbroek, the Netherlands. ${ }^{3}$ Department of Rehabilitation Medicine, Maastricht University Medical Centre, Maastricht, the Netherlands.

\section{Authors' contributions}

$\mathrm{RL}$ participated in drafting the manuscript, carried out the literature search, participated in the screening of the articles, identified and evaluated the included instruments and participated in interpreting the results. AT, YJ and HS participated in drafting the manuscript, screening the articles and interpreting the results. Furthermore, AT, YJ and HS critically revised the intellectual content of the article. RS participated in drafting the manuscript and interpreting the results and critically revised the intellectual content of the article. All authors read and approved the final manuscript.

\section{Competing interests}

The authors declare that they have no competing interests.

Received: 20 October 2011 Accepted: 12 April 2012

Published: 12 April 2012

\section{References}

1. Dobkin $\mathrm{BH}$ : Motor rehabilitation after stroke, traumatic brain, and spinal cord injury: common denominators within recent clinical trials. Curr Opin Neurol 2009, 22(6):563-569.

2. Blair E: Epidemiology of the cerebral palsies. Orthop Clin North Am 2010, 41(4):441-455.

3. Wolfe CD: The impact of stroke. Br Med Bull 2000, 56(2):275-286.

4. Nichols-Larsen DS, Clark PC, Zeringue A, Greenspan A, Blanton S: Factors influencing stroke survivors' quality of life during subacute recovery. Stroke 2005, 36(7):1480-1484. 
5. Tyson S, Turner G: Discharge and follow-up for people with stroke: what happens and why. Clin Rehabil 2000, 14(4):381-392.

6. Pagliano E, Andreucci E, Bono R, Semorile C, Brollo L, Fedrizzi E: Evolution of upper limb function in children with congenital hemiplegia. Neurol Sci 2001, 22(5):371-375.

7. Broeks JG, Lankhorst GJ, Rumping K, Prevo AHJ: The long-term outcome of arm function after stroke: results of a follow-up study. Disabil Rehabil 1999, 21(8):357-364.

8. Arner M, Eliasson AC, Nicklasson S, Sommerstein K, Hagglund G: Hand function in cerebral palsy. Report of 367 children in a population-based longitudinal health care program. J Hand Surg Am 2008, 33(8):1337-1347.

9. van Eck M, Dallmeijer AJ, van Lith IS, Voorman JM, Becher J: Manual ability and its relationship with daily activities in adolescents with cerebral palsy. J Rehabil Med 2010, 42(5):493-498.

10. International Classification of Functioning, Disability and Health (ICF). [http://www.who.int/classifications/icf/en].

11. Spooren Al, Janssen-Potten YJ, Post MW, Kerckhofs E, Nene A, Seelen HA: Measuring change in arm hand skilled performance in persons with a cervical spinal cord injury: responsiveness of the Van Lieshout Test. Spinal Cord 2006, 44(12):772-779.

12. Timmermans AA, Seelen HA, Willmann RD, Kingma H: Technology-assisted training of arm-hand skills in stroke: concepts on reacquisition of motor control and therapist guidelines for rehabilitation technology design. $J$ Neuroeng Rehabil 2009, 6:1.

13. Arnould C, Penta M, Thonnard JL: Hand impairments and their relationship with manual ability in children with cerebral palsy. J Rehabil Med 2007, 39(9):708-714

14. Burridge JH, Turk R, Notley SV, Pickering RM, Simpson DM: The relationship between upper limb activity and impairment in post-stroke hemiplegia. Disabil Rehabil 2009, 31(2):109-117.

15. Fisher AG, Jones KB: In Assessment of Motor and Process Skills. Volume 1: Development, Standardization and Administration Manual. Volume 1.. Seven edition. Three Star Press, Inc.; 2010.

16. Van Heugten C, Dekker J, Deelman BG, Van Dijk AJ, Stehmann-Saris JC, Kinebanian A: Measuring disabilities in stroke patients with apraxia: A validation study of an observational method. Neuropsychol Rehabil 2000, 10(4):401-414.

17. Kopp B, Kunkel A, Flor H, Platz T, Rose U, Mauritz KH, Gresser K, McCulloch KL, Taub E: The Arm Motor Ability Test: reliability, validity, and sensitivity to change of an instrument for assessing disabilities in activities of daily living. Arch Phys Med Rehabil 1997, 78(6):615-620.

18. Barreca S, Gowland CK, Stratford P, Huijbregts M, Griffiths J, Torresin W, Dunkley M, Miller P, Masters L: Development of the Chedoke Arm and Hand Activity Inventory: theoretical constructs, item generation, and selection. Top Stroke Rehabil 2004, 11(4):31-42.

19. Barreca SR, Stratford PW, Lambert CL, Masters LM, Streiner DL: Test-retest reliability, validity, and sensitivity of the Chedoke arm and hand activity inventory: a new measure of upper-limb function for survivors of stroke. Arch Phys Med Rehabil 2005, 86(8):1616-1622.

20. Heller A, Wade DT, Wood VA, Sunderland A, Hewer RL, Ward E: Arm function after stroke: measurement and recovery over the first three months. J Neurol Neurosurg Psychiatry 1987, 50(6):714-719.

21. Kruitwagen-van Reenen ET, Post MW, Mulder-Bouwens K, Visser-Meily JM: A simple bedside test for upper extremity impairment after stroke: validation of the Utrecht Arm/Hand Test. Disabil Rehabil 2009, 31(16):1338-1343.

22. Desrosiers J, Hebert R, Dutil E, Bravo G: Development and reliability of an upper extremity function test for the eldeerly: The TEMPA. Can J Occup Ther 1993, 60:9-16.

23. Desrosiers J, Hebert R, Dutil E, Bravo G, Mercier L: Validity of the TEMPA: A Measurement Instrument for Upper Extremtity Performance. Occup Ther J Res 1994, 14(4):267-281.

24. Suzuki M, Yamada S, Omori M, Hatakeyama M, Sugimura Y, Matsushita $K$, Tagawa Y: Development of the upper-body dressing scale for a buttoned shirt: a preliminary correlational study. Am J Phys Med Rehabil 2008, 87(9):740-749.

25. Aarts $\mathrm{PB}$, Jongerius $\mathrm{PH}$, Aarts MA, Van Hartingsveldt MJ, Anderson PG, Beumer A: A pilot study of the Video Observations Aarts and Aarts (VOAA): a new software program to measure motor behaviour in children with cerebral palsy. Occup Ther Int 2007, 14(2):113-122.
26. Aarts $P B$, Jongerius $P H$, Geerdink $Y A$, Geurts $A C$ : Validity and reliability of the VOAA-DDD to assess spontaneous hand use with a video observation tool in children with spastic unilateral cerebral palsy. BMC Musculoskelet Disord 2009, 10:145.

27. Uswatte G, Taub E: Implications of the Learned Nonuse Formulation for Measuring Rehabilitation Outcomes: Lessons From Constraint-Induced Movement Therapy. Rehabil Psychol 2005, 50(1):34-42.

28. Yozbatiran N, Der-Yeghiaian L, Cramer SC: A standardized approach to performing the action research arm test. Neurorehabil Neural Repair 2008 , 22(1):78-90.

29. Wilson DJ, Baker LL, Craddock JA: Functional test for the hemiparetic upper extremity. Am J Occup Ther 1984, 38(3):159-164.

30. Jebsen RH, Taylor N, Trieschmann RB, Trotter MJ, Howard LA: An objective and standardized test of hand function. Arch Phys Med Rehabil 1969, 50(6):311-319

31. Bovend'Eerdt TJH, Dawes H, Johansen-Berg H, Wade DT: Evaluation of the Modified Jebsen Test of Hand Function and the University of Maryland Arm Questionnaire for Stroke. Clin Rehabil 2004, 18(2):195-202.

32. Beebe JA, Lang CE: Relationships and responsiveness of six upper extremity function tests during the first six months of recovery after stroke. J Neurol Phys Ther 2009, 33(2):96-103.

33. Bourke-Taylor H: Melbourne Assessment of Unilateral Upper Limb Function: construct validity and correlation with the Pediatric Evaluation of Disability Inventory. Dev Med Child Neurol 2003, 45(2):92-96.

34. Randall M, Carlin JB, Chondros P, Reddihough D: Reliability of the Melbourne assessment of unilateral upper limb function. Dev Med Child Neurol 2001, 43(11):761-767.

35. Van de Winckel A, Feys $H$, van der Knaap S, Messerli R, Baronti F, Lehmann R, Van Hemelrijk B, Pante F, Perfetti C, De Weerdt W: Can quality of movement be measured? Rasch analysis and inter-rater reliability of the Motor Evaluation Scale for Upper Extremity in Stroke Patients (MESUPES). Clin Rehabil 2006, 20(10):871-884.

36. Nakamura R, Moriyama S, Yamada Y, Seki K: Recovery of impaired motor function of the upper extremity after stroke. Tohoku J Exp Med 1992, 168(1):11-20

37. Miyamoto S, Kondo T, Suzukamo Y, Michimata A, Izumi S: Reliability and validity of the Manual Function Test in patients with stroke. Am J Phys Med Rehabil 2009, 88(3):247-255.

38. DeMatteo C, Law M, Russell D, Pollock N, Rosenbaum P, Walter S: The Reliability and Validity of the Quality of Upper Extremity Skills Test. Phys Occup Ther Pediatr 1993, 13(2):1-18.

39. Davids JR, Peace LC, Wagner LV, Gidewall MA, Blackhurst DW, Roberson WM: Validation of the Shriners Hospital for Children Upper Extremity Evaluation (SHUEE) for children with hemiplegic cerebral palsy. J Bone Joint Surg Am 2006, 88(2):326-333.

40. Wolf SL, Thompson PA, Morris DM, Rose DK, Winstein CJ, Taub E, Giuliani C, Pearson SL: The EXCITE trial: attributes of the Wolf Motor Function Test in patients with subacute stroke. Neurorehabil Neural Repair 2005, 19(3):194-205.

41. Lin J, Hsu M, Sheu C, Wu T, Lin R, Chen C, Hsieh C: Psychometric comparisons of 4 measures for assessing upper-extremity function in people with stroke. Phys Ther 2009, 89(8):840-850.

42. Penta M, Thonnard JL, Tesio L: ABILHAND: a Rasch-built measure of manual ability. Arch Phys Med Rehabil 1998, 79(9):1038-1042.

43. Penta M, Tesio L, Arnould C, Zancan A, Thonnard J: The ABILHAND Questionnaire as a measure of manual ability in chronic stroke patients: Rasch-based validation and relationship to upper limb impairment. Stroke 2001, 32(7):1627-1634.

44. Arnould C, Penta M, Renders A, Thonnard JL: ABILHAND-Kids: a measure of manual ability in children with cerebral palsy. Neurology 2004, 63(6):1045-1052.

45. Law M, Baptiste S, McColl M, Opzoomer A, Polatajko H, Pollock N: The Canadian occupational performance measure: an outcome measure for occupational therapy. Can J Occup Ther 1990, 57(2):82-87.

46. Cup EH, Scholte op Reimer WJ, Thijssen MC, van Kuyk-Minis MA: Reliability and validity of the Canadian Occupational Performance Measure in stroke patients. Clin Rehabil 2003, 17(4):402.

47. Cusick A, Lannin NA, Lowe K: Adapting the Canadian Occupational Performance Measure for use in a paediatric clinical trial. Disabil Rehabil 2007, 29(10):761-766. 
48. Eyssen IC, Steultjens MP, Oud TA, Bolt EM, Maasdam A, Dekker J: Responsiveness of the canadian occupational performance measure. $J$ Rehabil Res Dev 2011, 48(5):517-528.

49. Sezer N, Yavuzer G, Sivrioglu K, Basaran P, Koseoglu BF: Clinimetric properties of the Duruoz hand index in patients with stroke. Arch Phys Med Rehabil 2007, 88(3):309-314.

50. Ertzgaard $P$, Ward $A B$, Wissel J, Borg J: Practical considerations for goal attainment scaling during rehabilitation following acquired brain injury. J Rehabil Med 2011, 43(1):8-14.

51. Steenbeek D, Ketelaar M, Galama K, Gorter JW: Goal attainment scaling in paediatric rehabilitation: a critical review of the literature. Dev Med Child Neurol 2007, 49(7):550-556.

52. Hurn J, Kneebone I, Cropley M: Goal setting as an outcome measure: A systematic review. Clin Rehabil 2006, 20(9):756-772.

53. Blennerhassett JM, Carey LM, Matyas TA: Clinical measures of handgrip limitation relate to impaired pinch grip force control after stroke. $J$ Hand Ther 2008, 21(3):245-252, quiz 253.

54. van der Lee $\mathrm{H}$, Beckerman $\mathrm{H}$, Knol DL, de Vet HC, Bouter LM: Clinimetric properties of the motor activity log for the assessment of arm use in hemiparetic patients. Stroke 2004, 35(6):1410-1414.

55. Taub E, Ramey SL, DeLuca S, Echols K: Efficacy of constraint-induced movement therapy for children with cerebral palsy with asymmetric motor impairment. Pediatrics 2004, 113(2):305-312

56. Wallen M, Bundy A, Pont K, Ziviani J: Psychometric properties of the Pediatric Motor Activity Log used for children with cerebral palsy. Dev Med Child Neurol 2009, 51(3):200-208.

57. Tucker CA, Haley SM, Dumas HM, Fragala-Pinkham M, Watson K, Gorton G, Montpetit K, Bilodeau N: Physical function for children and youth with cerebral palsy: Item bank development for computer adaptive testing. J Pediatr Rehabil Med 2008, 1(3):245-253.

58. Tucker CA, Montpetit K, Bilodeau N, Dumas HM, Fragala-Pinkham MA, Watson K, Gorton GE, Ni P, Hambleton RK, Mulcahey MJ, et al: Development of a parent-report computer-adaptive test to assess physical functioning in children with cerebral palsy II: upper-extremity skills. Dev Med Child Neurol 2009, 51(9):725-731.

59. Haley SM, Fragala-Pinkham MA, Dumas HM, Ni P, Gorton GE, Watson K, Montpetit K, Bilodeau N, Hambleton RK, Tucker CA: Evaluation of an item bank for a computerized adaptive test of activity in children with cerebral palsy. Phys Ther 2009, 89(6):589-600.

60. Gebruers N, Vanroy C, Truijen S, Engelborghs S, De Deyn PP: Monitoring of physical activity after stroke: a systematic review of accelerometry-based measures. Arch Phys Med Rehabil 2010, 91(2):288-297.

61. Krumlinde-Sundholm L: Development of the assisting hand assessment: a Raschbuilt measure intended for children with unilateral upper limb impairments. Scand J Occup Ther 2003, 10:16-26.

62. Krumlinde-Sundholm L, Holmefur M, Kottorp A, Eliasson AC: The Assisting Hand Assessment: current evidence of validity, reliability, and responsiveness to change. Dev Med Child Neurol 2007, 49(4):259-264.

63. Uswatte $G$, Hobbs Qadri L: A behavioral observation system for quantifying arm activity in daily life after stroke. Rehabil Psychol 2009, 54(4):398-403.

64. Duncan PW, Jorgensen HS, Wade DT: Outcome measures in acute stroke trials: a systematic review and some recommendations to improve practice. Stroke 2000, 31(6):1429-1438.

65. Houwink A, Aarts PB, Geurts AC, Steenbergen B: A neurocognitive perspective on developmental disregard in children with hemiplegic cerebral palsy. Res Dev Disabil 2011, 32(6):2157-2163.

66. Mark W, Taub E: Constraint-induced movement therapy for chronic stroke hemiparesis and other disabilities. Restor Neurol Neurosci 2004, 22(3-5):317-336.

67. Vega-Gonzalez A, Granat MH: Continuous monitoring of upper-limb activity in a free-living environment. Arch Phys Med Rehabil 2005, 86(3):541-548

68. de Niet M, Bussmann JB, Ribbers GM, Stam HJ: The stroke upper-limb activity monitor: its sensitivity to measure hemiplegic upper-limb activity during daily life. Arch Phys Med Rehabil 2007, 88(9):1121-1126.

69. Greaves S, Imms C, Dodd K, Krumlinde-Sundholm L: Assessing bimanual performance in young children with hemiplegic cerebral palsy: a systematic review. Dev Med Child Neurol 2010, 52(5):413-421.

70. van de Ven-Stevens LA, Munneke M, Terwee $C B$, Spauwen $\mathrm{PH}$, van der Linde $\mathrm{H}$ : Clinimetric properties of instruments to assess activities in patients with hand injury: a systematic review of the literature. Arch Phys Med Rehabil 2009, 90(1):151-169.

71. Eliasson A, Krumlinde-Sundholm L, RÃ $₫$ sblad B, Beckung E, Arner M, Ohrvall A, Rosenbaum P: The Manual Ability Classification System (MACS) for children with cerebral palsy: scale development and evidence of validity and reliability. Dev Med Child Neurol 2006, 48(7):549-554

72. Waters PM, Zurakowski D, Patterson P, Bae DS, Nimec D: Interobserver and intraobserver reliability of therapist-assisted videotaped evaluations of upper-limb hemiplegia. J Hand Surg Am 2004, 29(2):328-334

73. Gordon AM, Hung YC, Brandao M, Ferre CL, Kuo HC, Friel K, Petra E, Chinnan A, Charles JR: Bimanual training and constraint-induced movement therapy in children with hemiplegic cerebral palsy: a randomized trial. Neurorehabil Neural Repair 2011, 25(8):692-702.

74. Harvey A, Robin J, Morris ME, Graham HK, Baker R: A systematic review of measures of activity limitation for children with cerebral palsy. Dev Med Child Neurol 2008, 50(3):190-198.

75. Sunderland A: Recovery of ipsilateral dexterity after stroke. Stroke 2000, 31(2):430-433

76. Postans N, Wright P, Bromwich W, Wilkinson I, Farmer SE, Swain I: The combined effect of Dynamic splinting and Neuromuscular electrical stimulation in reducing wrist and elbow contractures in six children with Cerebral palsy. Prosthet Orthot Int 34(1):10-19.

77. Staubli $P$, Nef $T$, Klamroth-Marganska $V$, Riener R: Effects of intensive arm training with the rehabilitation robot ARMin II in chronic stroke patients: four single-cases. J Neuroeng Rehabil 2009, 6:46.

78. McEwen SE, Huijbregts MP, Ryan JD, Polatajko HJ: Cognitive strategy use to enhance motor skill acquisition post-stroke: a critical review. Brain Inj 2009, 23(4):263-277.

79. Broeks JG, Lankhorst GJ, Rumping K, Prevo AHJ: The long-term outcome of arm function after stroke: results of a follow-up study. Disabil Rehabil 1999, 21(8):357-364.

80. Wade DT, Langton-Hewer R, Wood VA, Skilbeck CE, Ismail HM: The hemiplegic arm after stroke: measurement and recovery. J Neurol Neurosurg Psychiatry 1983, 46(6):521-524

81. Sung I, Ryu J, Pyun S, Yoo S, Song W, Park M: Efficacy of forced-use therapy in hemiplegic cerebral palsy. Arch Phys Med Rehabil 2005, 86(11):2195-2198.

82. Bumin G, Kavak ST: An investigation of the factors affecting handwriting skill in children with hemiplegic cerebral palsy. Disabil Rehabil 32(8):692-703.

83. Smania N, Gambarin M, Tinazzi M, Picelli A, Fiaschi A, Moretto G, Bovi $P$, Paolucci S: Are indexes of arm recovery related to daily life autonomy in patients with stroke? Eur J Phys Rehabil Med 2009, 45(3):349-354

84. Charles JR, Wolf SL, Schneider JA, Gordon AM: Efficacy of a child-friendly form of constraint-induced movement therapy in hemiplegic cerebral palsy: a randomized control trial. Dev Med Child Neurol 2006, 48(8):635-642.

85. Spaulding SJ, Strachota E, McPherson JJ, Kuphal M, Ramponi M: Wrist muscle tone and self-care skill in persons with hemiparesis. Am J Occup Ther 1989, 43(1):11-16.

86. Crocker MD, MacKay-Lyons M, McDonnell E: Forced use of the upper extremity in cerebral palsy: a single-case design. Am J Occup Ther 1997, 51(10):824-833.

87. Kinghorn J: Upper extremity functional changes following selective posterior rhizotomy in children with cerebral palsy. Am J Occup Ther 1992, 46(6):502-507.

88. Karabegovic A, Kapidzic-Durakovic S, Ljuca F: Laser therapy of painful shoulder and shoulder-hand syndrome in treatment of patients after the stroke. Bosn J Basic Med Sci 2009, 9(1):59-65.

89. Van Heest $A E$, Strothman D: Wrist arthrodesis in cerebral palsy. $J$ Hand Surg Am 2009, 34(7):1216-1224.

90. van Dijk H, Jannink MJ, Hermens HJ: Effect of augmented feedback on motor function of the affected upper extremity in rehabilitation patients: a systematic review of randomized controlled trials. J Rehabil Med 2005, 37(4):202-211.

91. Coderre AM, Zeid AA, Dukelow SP, Demmer MJ, Moore KD, Demers MJ, Bretzke H, Herter TM, Glasgow Jl, Norman KE et al: Assessment of upperlimb sensorimotor function of subacute stroke patients using visually guided reaching. Neurorehabilitation \& Neural Repair 24(6):528-541.

92. van der Lee $J \mathrm{H}$, Snels IA, Beckerman $H$, Lankhorst GJ, Wagenaar RC, Bouter LM: Exercise therapy for arm function in stroke patients: a 
systematic review of randomized controlled trials. Clin Rehabil 2001, 15(1):20-31.

93. Størvold GV, Jahnsen R: Intensive motor skills training program combining group and individual sessions for children with cerebral palsy. Pediatric Physical Therapy 22(2):150-159.

94. Takahashi CD, Der-Yeghiaian L, Le V, Motiwala RR, Cramer SC: Robot-based hand motor therapy after stroke..

95. Chan MK, Tong RK, Chung KY: Bilateral upper limb training with functional electric stimulation in patients with chronic stroke. Neurorehabil Neural Repair 2009, 23(4):357-365.

96. Smania N, Aglioti SM, Cosentino A, Camin M, Gandolfi M, Tinazzi M, Fiaschi A, Faccioli S: A modified constraint-induced movement therapy (CIT) program improves paretic arm use and function in children with cerebral palsy. Eur J Phys Rehabil Med 2009, 45(4):493-500.

97. Kinghorn J, Roberts G: The effect of an inhibitive weight-bearing splint on tone and function: a single-case study. Am J Occup Ther 1996, 50(10):807-815.

98. Autti-Ramo I, Larsen A, Peltonen J, Taimo A, von Wendt L: Botulinum toxin injection as an adjunct when planning hand surgery in children with spastic hemiplegia. Neuropediatrics 2000, 31(1):4-8

99. letswaart M, Johnston M, Dijkerman HC, Scott CL, Joice SA, Hamilton S, Macwalter RS: Recovery of hand function through mental practice: a study protocol. BMC Neurol 2006, 6:39.

100. Steenbergen B, Verrel J, Gordon AM: Motor planning in congenital hemiplegia. Disabil Rehabil 2007, 29(1):13-23.

101. Yozbatiran N, Donmez B, Kayak N, Bozan O: Electrical stimulation of wrist and fingers for sensory and functional recovery in acute hemiplegia. Clin Rehabil 2006, 20(1):4-11.

102. Barghout A, Alamri A, Eid M, El Saddik A: Haptic Rehabilitation Exercises Performance Evaluation Using Fuzzy Inference Systems. Medical Measurements and Applications, 2008 MeMeA 2008 IEEE International Workshop on: 9-10 May 20082008 2008, 13-18.

103. Breslin DM, Exner CE: Construct validity of the In-Hand Manipulation Test: a discriminant analysis with children without disability and children with spastic diplegia. Am J Occup Ther 1999, 53(4):381-386.

104. Therapy-based rehabilitation services for stroke patients at home. Cochrane Database Syst Rev 2003(1):CD002925.

105. Taub E, Griffin A, Nick J, Gammons K, Uswatte G, Law CR: Pediatric CI therapy for stroke-induced hemiparesis in young children. Dev Neurorehabil 2007, 10(1):3-18.

106. Watson MJ, Crosby P, Matthews M: An evaluation of the effects of a dynamic lycra orthosis on arm function in a late stage patient with acquired brain injury. Brain Inj 2007, 21(7):753-761.

107. Alberts JL, Butler AJ, Wolf SL: The effects of constraint-induced therapy on precision grip: a preliminary study. Neurorehabil Neural Repair 2004, 18(4):250-258.

108. Steenbergen B, Veringa A, de Haan A, Hulstijn W: Manual dexterity and keyboard use in spastic hemiparesis: a comparison between the impaired hand and the 'good' hand on a number of performance measures. Clin Rehabil 1998, 12(1):64-72.

109. Schneiberg S, McKinley P, Gisel E, Sveistrup H, Levin MF: Reliability of kinematic measures of functional reaching in children with cerebral palsy. Dev Med Child Neurol 52(7):e167-173.

110. Cope SM, Forst HC, Bibis D, Liu XC: Modified constraint-induced movement therapy for a 12-month-old child with hemiplegia: a case report. Am J Occup Ther 2008, 62(4):430-437.

111. Dursun N, Dursun E, Sade I, Cekmece C: Constraint induced movement therapy: efficacy in a Turkish stroke patient population and evaluation by a new outcome measurement tool. Eur J Phys Rehabil Med 2009, 45(2):165-170.

112. Carod-Artal FJ, Coral LF, Trizotto DS, Moreira CM: The stroke impact scale 3.0: evaluation of acceptability, reliability, and validity of the Brazilian version. Stroke 2008, 39(9):2477-2484.

113. Welmer AK, Holmqvist LW, Sommerfeld DK: Limited fine hand use after stroke and its association with other disabilities. J Rehabil Med 2008, 40(8):603-608.

114. Yoo E, Park E, Chung B: Mental practice effect on line-tracing accuracy in persons with hemiparetic stroke: a preliminary study. Arch Phys Med Rehabil 2001, 82(9):1213-1218.

115. Shaw L, Rodgers H, Price C, van Wijck F, Shackley P, Steen N, Barnes M, Ford G, Graham L: BoTULS: a multicentre randomised controlled trial to evaluate the clinical effectiveness and cost-effectiveness of treating upper limb spasticity due to stroke with botulinum toxin type A. Health Technol Assess 14(26):1-113, iii-iv.

116. van Eck M, Dallmeijer AJ, van Lith IS, Voorman JM, Becher J: Manual ability and its relationship with daily activities in adolescents with cerebral palsy. J Rehabil Med 42(5):493-498.

117. Blank R, von Kries R, Hesse S, von Voss H: Conductive education for children with cerebral palsy: effects on hand motor functions relevant to activities of daily living. Arch Phys Med Rehabil 2008, 89(2):251-259.

118. Sterr A, Freivogel S, Schmalohr D: Neurobehavioral aspects of recovery: assessment of the learned nonuse phenomenon in hemiparetic adolescents. Arch Phys Med Rehabil 2002, 83(12):1726-1731.

119. Weber DJ, Skidmore ER, Niyonkuru C, Chang CL, Huber LM, Munin MC: Cyclic functional electrical stimulation does not enhance gains in hand grasp function when used as an adjunct to onabotulinumtoxinA and task practice therapy: a single-blind, randomized controlled pilot study. Arch Phys Med Rehabil 91(5):679-686.

120. Sunderland A, Tinson D, Bradley L, Hewer RL: Arm function after stroke. An evaluation of grip strength as a measure of recovery and a prognostic indicator. J Neurol Neurosurg Psychiatry 1989, 52(11):1267-1272.

121. Santos M, Zahner LH, McKiernan BJ, Mahnken JD, Quaney B: Neuromuscular electrical stimulation improves severe hand dysfunction for individuals with chronic stroke: a pilot study. J Neurol Phys Ther 2006, 30(4):175-183.

122. Radell U, Tillberg E, Mattsson E, Amark P: Postnatal cerebral infection leading to hemiplegic cerebral palsy: functional limitations and disability of 13 children in Sweden. Disabil Rehabil 2008, 30(25):1910-1919.

123. Bhakta B, Cozens A, Farrin A, Ford G, Langan D, McCabe C, et al: DARS. Dopamine Augmented Rehabilitation in Stroke. Does Co-careldopa treatment in combination with routine NHS occupational and physical therapy, delivered early after stroke within a stroke service, improve functional recovery including walking and arm function?[http://www. eme.ac.uk/projectfiles/084361 protocol.pdf].

124. Turton AJ, Fraser CM: A test battery to measure the recovery of voluntary movement control following stroke. Int Rehabil Med 1986, 8(2):74-78.

125. Lewin JE, Mix CM, Gaebler-Spira D: Self-help and upper extremity changes in 36 children with cerebral palsy subsequent to selective posterior rhizotomy and intensive occupational and physical therapy. Phys Occup Ther Pediatr 1993, 13(3):25-42.

126. Ashford S, Turner-Stokes L: Management of shoulder and proximal upper limb spasticity using botulinum toxin and concurrent therapy interventions: a preliminary analysis of goals and outcomes. Disabil Rehabil 2009, 31(3):220-226.

127. Siebers A, A-berg U, Skargren E: Improvement and impact of initial motor skill after intensive rehabilitation - Cl-therapy in patients with chronic hemiplegia. A follow-up study. Adv Physiother 2006, 8(4):146-153.

128. Olesch CA, Greaves S, Imms C, Reid SM, Graham HK: Repeat botulinum toxin-A injections in the upper limb of children with hemiplegia: a randomized controlled trial. Dev Med Child Neurol 52(1):79-86.

129. Wesdock KA, Kott K, Sharps C: Pre- and postsurgical evaluation of hand function in hemiplegic cerebral palsy: exemplar cases. J Hand Ther 2008, 21(4):386-397.

130. Barnes D, Linton JL, Sullivan E, Bagley A, Oeffinger D, Abel M, Damiano D, Gorton G, Nicholson D, Romness M, et al: Pediatric outcomes data collection instrument scores in ambulatory children with cerebral palsy: an analysis by age groups and severity level. J Pediatr Orthop 2008, 28(1):97-102.

131. Burtner PA, Poole JL, Torres T, Medora AM, Abeyta R, Keene J, Qualls C: Effect of wrist hand splints on grip, pinch, manual dexterity, and muscle activation in children with spastic hemiplegia: a preliminary study. J Hand Ther 2008, 21(1):36-42, quiz 43.

132. de Kroon JR, ljzerman MJ, Chae J, Lankhorst GJ, Zilvold G: Relation between stimulation characteristics and clinical outcome in studies using electrical stimulation to improve motor control of the upper extremity in stroke. J Rehabil Med 2005, 37(2):65-74.

133. McEwen SE, Polatajko HJ, Huijbregts MPJ, Ryan JD: Exploring a cognitivebased treatment approach to improve motor-based skill performance in chronic stroke: results of three single case experiments. Brain Inj 2009, 23(13-14):1041-1053. 
134. Yelnik A, Bonan I, Debray M, Lo E, Gelbert F, Bussell B: Changes in the execution of a complex manual task after ipsilateral ischemic cerebral hemispheric stroke. Arch Phys Med Rehabil 1996, 77(8):806-810.

135. Boian R, Sharma A, Han C, Merians A, Burdea G, Adamovich S, Recce M, Tremaine M, Poizner $\mathrm{H}$ : Virtual reality-based post-stroke hand rehabilitation. Stud Health Technol Inform 2002, 85:64-70.

136. van der Lee JH, Wagenaar RC, Lankhorst GJ, Vogelaar TW, Devillé WL, Bouter LM: Forced use of the upper extremity in chronic stroke patients: results from a single-blind randomized clinical trial. Stroke; a journal of cerebral circulation 1999, 30(11):2369-2375.

137. Schaechter JD, Perdue KL: Enhanced cortical activation in the contralesional hemisphere of chronic stroke patients in response to motor skill challenge..

138. Stoykov ME: Bilateral training for upper extremity hemiparesis in stroke. Ph.D University of Illinois at Chicago, Health Sciences Center; 2008.

139. Hiraoka K: Rehabilitation effort to improve upper extremity function in post-stroke patients: a meta-analysis. J Phys Ther Sci 2001, 13(1):5-9.

140. Thrasher TA, Zivanovic V, Mcllroy W, Popovic MR: Rehabilitation of reaching and grasping function in severe hemiplegic patients using functional electrical stimulation therapy. Neurorehabil Neural Repair 2008, 22(6):706-714

141. Eliasson AC, Bonnier B, Krumlinde-Sundholm L: Clinical experience of constraint induced movement therapy in adolescents with hemiplegic cerebral palsy-a day camp model. Dev Med Child Neurol 2003, 45(5):357-359.

142. Almeida GL, Campbell SK, Girolami GL, Penn RD, Corcos DM: Multidimensional assessment of motor function in a child with cerebral palsy following intrathecal administration of baclofen. Phys Ther 1997, 77(7):751-764.

143. Kawahira K, Shimodozono M, Etoh S, Kamada K, Noma T, Tanaka N: Effects of intensive repetition of a new facilitation technique on motor functional recovery of the hemiplegic upper limb and hand. Brain Injury 24(10):1202-1213.

144. Brogardh C, Sjölund BH: Constraint-induced movement therapy in patients with stroke: a pilot study on effects of small group training and of extended mitt use. Clin Rehabil 2006, 20(3):218-227.

145. Talbot ML, Junkala J: The effects of auditorally augmented feedback on the eye-hand coordination of students with cerebral palsy. Am J Occup Ther 1981, 35(8):525-528.

146. Wolf TM, Clinkscales CM, Hamlin C: Flexor carpi ulnaris tendon transfers in cerebral palsy. J Hand Surg Br 1998, 23(3):340-343.

147. Vega-Gonzalez A, Bain BJ, Dall PM, Granat MH: Continuous monitoring of upper-limb activity in a free-living environment: a validation study. Med Biol Eng Comput 2007, 45(10):947-956.

148. Sullivan JE, Hedman LD: A home program of sensory and neuromuscular electrical stimulation with upper-limb task practice in a patient 5 years after a stroke. Phys Ther 2004, 84(11):1045-1054.

149. Henderson A, Korner-Bitensky N, Levin M: Virtual reality in stroke rehabilitation: a systematic review of its effectiveness for upper limb motor recovery. Top Stroke Rehabil 2007, 14(2):52-61.

150. Duff M, Attygalle S, He J, Rikakis T: A portable, low-cost assessment device for reaching times. Conf Proc IEEE Eng Med Biol Soc 2008, 2008:4150-4153.

151. Lewis GN, Byblow WD: Neurophysiological and behavioral adaptations to a bilateral training intervention in individuals following stroke.

152. Walker CM, Sunderland A, Sharma J, Walker MF: The impact of cognitive impairment on upper body dressing difficulties after stroke: a video analysis of patterns of recovery. J Neurol Neurosurg Psychiatry 2004, 75(1):43-48

153. Sheppard L, Mudie H, Froude E: An investigation of bilateral isokinematic training and neurodevelopmental therapy in improving use of the affected hand in children with hemiplegia. Phys Occup Ther Pediatr 2007 27(1):5-25.

154. Thilmann A, Nachtmann A, Scharff A: [Neurological Reha-Score. An instrument to measure outcome and expenditure of neurologic rehabilitation]. Nervenarzt 2006, 77(12):1456-1463.

155. Reeuwijk A, van Schie PE, Becher JG, Kwakkel G: Effects of botulinum toxin type $A$ on upper limb function in children with cerebral palsy: a systematic review. Clin Rehabil 2006, 20(5):375-387.

156. Shah SK, Corones J: Volition following hemiplegia. Arch Phys Med Rehabil 1980, 61(11):523-528
157. Waller SM, Whitall J: Hand dominance and side of stroke affect rehabilitation in chronic stroke. Clin Rehabil 2005, 19(5):544-551.

158. Yagura H, Miyai I, Seike Y, Suzuki T, Yanagihara T: Benefit of inpatient multidisciplinary rehabilitation up to 1 year after stroke. Arch Phys Med Rehabil 2003, 84(11):1687-1691.

159. Yang TF, Fu CP, Kao NT, Chan RC, Chen SJ: Effect of botulinum toxin type A on cerebral palsy with upper limb spasticity. Am J Phys Med Rehabil 2003, 82(4):284-289.

160. Sunderland A, Bowers MP, Sluman S, Wilcock DJ, Ardron ME: Impaired dexterity of the ipsilateral hand after stroke and the relationship to cognitive deficit. Stroke 1999, 30(5):949-955.

161. Sheikh K, Smith DS, Meade TW, Goldenberg E, Brennan PJ, Kinsella G: Repeatability and validity of a modified activities of daily living (ADL) index in studies of chronic disability. Int Rehabil Med 1979, 1(2):51-58.

162. Brorsson B, Asberg KH: Katz index of independence in ADL. Reliability and validity in short-term care. Scand J Rehabil Med 1984, 16(3):125-132.

163. Skidmore ER, Rogers JC, Chandler LS, Holm MB: Dynamic interactions between impairment and activity after stroke: examining the utility of decision analysis methods. Clin Rehabil 2006, 20(6):523-535.

164. Lincoln NB, Edmans JA: A re-validation of the Rivermead ADL scale for elderly patients with stroke. Age Ageing 1990, 19(1):19-24.

165. Carr JH, Shepherd RB, Nordholm L, Lynne D: Investigation of a new motor assessment scale for stroke patients. Phys Ther 1985, 65(2):175-180.

166. Fletcher-Smith J, Walker M, Sunderland A, Garvey K, Wan A, Turner H: An interrater reliability study of the Nottingham Stroke Dressing Assessment. Br J Occup Ther 2010, 73(12):570-578.

167. Quinn TJ, Langhorne P, Stott DJ: Barthel index for stroke trials: development, properties, and application. Stroke 42(4):1146-1151.

168. Van Bennekom CA, Jelles F, Lankhorst GJ: Rehabilitation Activities Profile: the ICIDH as a framework for a problem-oriented assessment method in rehabilitation medicine. Disabil Rehabil 1995, 17(3-4):169-175.

169. Klein RM, Bell BJ: Klein-Bell Activities of Daily Living Scale .

170. Lincoln N, Leadbitter D: Assessment of motor function in stroke patients. Physiotherapy 1979, 65(2):48-51

171. Sodring KM, Bautz-Holter E, Ljunggren AE, Wyller TB: Description and validation of a test of motor function and activities in stroke patients. The Sodring Motor Evaluation of Stroke Patients. Scand J Rehabil Med 1995, 27(4):211-217.

172. Keith RA, Granger CV, Hamilton BB, Sherwin FS: The functional independence measure: a new tool for rehabilitation. Adv Clin Rehabil 1987, 1:6-18

173. Msall ME, DiGaudio K, Rogers BT, LaForest S, Catanzaro NL, Campbell J, Wilczenski F, Duffy LC: The Functional Independence Measure for Children (WeeFIM). Conceptual basis and pilot use in children with developmental disabilities. Clin Pediatr (Phila) 1994, 33(7):421-430.

174. Unsworth CA: Measuring Outcomes using the Australian Therapy Outcome Measures for Occupational Therapy (AusTOMs-OT): Data Description and Tool Sensitivity. Br J Occup Ther 2005, 68(8):354-366.

175. Holbrook M, Skilbeck CE: An activities index for use with stroke patients. Age Ageing 1983, 12(2):166-170

176. Nouri FM, Lincoln NB: An extended activities of daily living scale for stroke patients. Clin Rehabil 1987, 1(4):301-305.

177. Varni JW, Burwinkle TM, Berrin SJ, Sherman SA, Artavia K, Malcarne VL, Chambers HG: The PedsQL in pediatric cerebral palsy: reliability, validity, and sensitivity of the Generic Core Scales and Cerebral Palsy Module. Dev Med Child Neurol 2006, 48(6):442-449.

178. Duncan PW, Wallace D, Lai SM, Johnson D, Embretson S, Laster LJ: The stroke impact scale version 2.0. Evaluation of reliability, validity, and sensitivity to change. Stroke 1999, 30(10):2131-2140.

179. Alon G, Dar A, Katz-Behiri D, Weingarden H, Nathan R: Efficacy of a hybrid upper limb neuromuscular electrical stimulation system in lessening selected impairments and dysfunctions consequent to cerebral damage. Journal of Neurologic Rehabilitation 1998, 12(2):73-79.

180. Kwakkel G, Wagenaar RC: Dynamics of functional recovery after cerebrovascular attack: effects of intensity of training of hand and walking skills [Dutch]. Nederlands Tijdschrift Voor Fysiotherapie 2000, 110(2):32-40.

181. Alon G, McBride K, Ring H: Improving selected hand functions using a noninvasive neuroprosthesis in persons with chronic stroke. J Stroke Cerebrovasc Dis 2002, 11(2):99-106. 
182. Woldag $\mathrm{H}$, Hummelsheim $\mathrm{H}$ : Is the reduction of spasticity by botulinum toxin a beneficial for the recovery of motor function of arm and hand in stroke patients? Eur Neurol 2003, 50(3):165-171.

183. Bowman MH, Taub E, Uswatte G, Delgado A, Bryson C, Morris DM, McKay S, Mark W: A treatment for a chronic stroke patient with a plegic hand combining $\mathrm{Cl}$ therapy with conventional rehabilitation procedures: case report. NeuroRehabilitation 2006, 21(2):167-176.

184. Huber M, Rabin B, Docan C, Burdea G, Nwosu ME, Abdelbaky M, Golomb MR: PlayStation 3-based tele-rehabilitation for children with hemiplegia. Virtual Rehabilitation, 2008: 25-27 Aug. 20082008 2008, 105-112.

185. Wolf SL, Lecraw DE, Barton LA, Jann BB: Forced use of hemiplegic upper extremities to reverse the effect of learned nonuse among chronic stroke and head-injured patients. Exp Neurol 1989, 104(2):125-132.

186. van Straten A, de Haan RJ, Limburg M, Schuling J, Bossuyt PM, van den Bos GA: A stroke-adapted 30-item version of the Sickness Impact Profile to assess quality of life (SA-SIP30). Stroke 1997, 28(11):2155-2161.

187. Byl N, Roderick J, Mohamed O, Hanny M, Kotler J, Smith A, Tang M, Abrams G: Effectiveness of sensory and motor rehabilitation of the upper limb following the principles of neuroplasticity: patients stable poststroke. Neurorehabil Neural Repair 2003, 17(3):176-191.

188. de Groot-Driessen D, van Heugten C: Speed of finger tapping as a predictor of functional outcome after unilateral stroke. Arch Phys Med Rehabil 2006, 87(1):40-44.

189. Kurtais Y, Kucukdeveci A, Elhan A, Yilmaz A, Kalli T, Tur BS, Tennant A: Psychometric properties of the Rivermead Motor Assessment: its utility in stroke. J Rehabil Med 2009, 41(13):1055-1061.

190. Wyller TB, Sodring KM, Sveen U, Ljunggren AE, Bautz-Holter E: Predictive validity of the Sodring Motor Evaluation of Stroke Patients (SMES). Scand J Rehabil Med 1996, 28(4):211-216.

191. Halsaa KE, Sodring KM, Bjelland E, Finsrud K, Bautz-Holter E: Inter-rater reliability of the Sodring Motor Evaluation of Stroke patients (SMES). Scand J Rehabil Med 1999, 31(4):240-243.

192. Asberg KH, Nydevik I: Early prognosis of stroke outcome by means of Katz Index of activities of daily living. Scand J Rehabil Med 1991, 23(4):187-191.

193. Malouin F, Pichard L, Bonneau C, Durand A, Corriveau D: Evaluating motor recovery early after stroke: comparison of the Fugl-Meyer Assessment and the Motor Assessment Scale. Arch Phys Med Rehabil 1994, 75(11):1206-1212.

194. English CK, Hillier SL, Stiller K, Warden-Flood A: The sensitivity of three commonly used outcome measures to detect change amongst patients receiving inpatient rehabilitation following stroke. Clin Rehabil 2006, 20(1):52-55.

195. Dodds TA, Martin DP, Stolov WC, Deyo RA: A validation of the functional independence measurement and its performance among rehabilitation inpatients. Arch Phys Med Rehabil 1993, 74(5):531-536.

196. Tur BS, Kucukdeveci AA, Kutlay S, Yavuzer G, Elhan AH, Tennant A: Psychometric properties of the WeeFIM in children with cerebral palsy in Turkey. Dev Med Child Neurol 2009, 51(9):732-738.

197. Ottenbacher KJ, Msall ME, Lyon N, Duffy LC, Ziviani J, Granger CV, Braun S, Feidler RC: The WeeFIM instrument: its utility in detecting change in children with developmental disabilities. Arch Phys Med Rehabil 2000, 81(10):1317-1326.

198. Unsworth CA, Duckett SJ, Duncombe D, Perry A, Skeat J, Taylor N: Validity of the AusTOM scales: a comparison of the AusTOMs and EuroQol-5D. Health Qual Life Outcomes 2004, 2:64.

199. Wu CY, Chuang LL, Lin KC, Horng YS: Responsiveness and validity of two outcome measures of instrumental activities of daily living in stroke survivors receiving rehabilitative therapies. Clin Rehabil 25(2):175-183.

200. Post MW, de Witte LP: Good inter-rater reliability of the Frenchay Activities Index in stroke patients. Clin Rehabil 2003, 17(5):548-552.

201. van Bennekom CA, Jelles F, Lankhorst GJ, Bouter LM: The Rehabilitation Activities Profile: a validation study of its use as a disability index with stroke patients. Arch Phys Med Rehabil 1995, 76(6):501-507.

202. Jelles F, Van Bennekom CA, Lankhorst GJ, Sibbel CJ, Bouter LM: Inter- and intrarater agreement of the Rehabilitation Activities Profile. J Clin Epidemiol 1995, 48(3):407-416.

203. van Bennekom CA, Jelles F, Lankhorst GJ, Bouter LM: Responsiveness of the rehabilitation activities profile and the Barthel index. J Clin Epidemiol 1996, 49(1):39-44.

\section{Pre-publication history}

The pre-publication history for this paper can be accessed here: http://www.biomedcentral.com/1471-2377/12/21/prepub

doi:10.1186/1471-2377-12-21

Cite this article as: Lemmens et al:: Valid and reliable instruments for arm-hand assessment at ICF activity level in persons with hemiplegia: a systematic review. BMC Neurology 2012 12:21.

\section{Submit your next manuscript to BioMed Central and take full advantage of:}

- Convenient online submission

- Thorough peer review

- No space constraints or color figure charges

- Immediate publication on acceptance

- Inclusion in PubMed, CAS, Scopus and Google Scholar

- Research which is freely available for redistribution 